\title{
Dietary zinc addition influenced zinc and lipid deposition in the fore- and mid-intestine of juvenile yellow catfish Pelteobagrus fulvidraco
}

\author{
Guang-Hui Chen ${ }^{1}$, Christer Hogstrand ${ }^{2}$, Zhi Luo ${ }^{1,3 *}$, Dian-Guang Zhang ${ }^{1}$, Shi-Cheng Ling ${ }^{1}$ and Kun Wu ${ }^{1}$ \\ ${ }^{1}$ Key Laboratory of Freshwater Animal Breeding, Ministry of Agriculture of P.R.C., Fishery College, Huazhong Agricultural \\ University, Wuban 430070, People's Republic of China \\ ${ }^{2}$ School of Medicine, King's College London, Diabetes and Nutritional Sciences Division, Franklin-Wilkins Building, 150 \\ Stamford Street, London SE1 9NH, UK \\ ${ }^{3}$ Collaborative Innovation Center for Efficient and Health Production of Fisheries in Hunan Province, Changde 415000, \\ People's Republic of China
}

(Submitted 22 May 2017 - Final revision received 18 July 2017 - Accepted 17 August 2017 - First published online 26 September 2017)

\section{Abstract}

The present study explored the mechanisms of dietary $\mathrm{Zn}$ influencing $\mathrm{Zn}$ and lipid deposition in the fore- and mid-intestine in yellow catfish Pelteobagrus fulvidraco, and investigated whether the mechanism was intestinal-region dependent. For this purpose, yellow catfish were fed three diets containing Zn levels of 8.83, 19.20 and $146.65 \mathrm{mg} \mathrm{Zn/kg}$, respectively. Growth performance, intestinal TAG and Zn contents as well as activities and mRNA expression of enzymes and genes involved in $\mathrm{Zn}$ transport and lipid metabolism in the fore- and mid-intestine were analysed. Dietary $\mathrm{Zn}$ increased $\mathrm{Zn}$ accumulation as well as activities of $\mathrm{Cu}-$, $\mathrm{Zn}$-superoxide dismutase and ATPase in the fore- and midintestine. In the fore-intestine, dietary Zn up-regulated mRNA levels of ZnT1, ZnT5, ZnT7, metallothionein (MT) and metal response elementbinding transcription factor-1 (MTF-1), but down-regulated mRNA levels of ZIP 4 and ZIP5. In the mid-intestine, dietary Zn up-regulated mRNA levels of ZnT1, ZnT5, ZnT7, MT and MTF-1, but down-regulated mRNA levels of ZIP4 and ZIP5. Dietary Zn reduced TAG content, downregulated activities of 6-phosphogluconate dehydrogenase (6PGD), glucose-6-phosphate dehydrogenase (G6PD), malic enzyme (ME) and fatty acid synthase (FAS) activities, and reduced mRNA levels of 6PGD, G6PD, FAS, PPAR $\gamma$ and sterol-regulator element-binding protein (SREBP-1), but up-regulated mRNA levels of carnitine palmitoyltransferase IA, hormone-sensitive lipase (HSLa), adipose TAG lipase (ATGL) and PPAR $\alpha$ in the fore-intestine. In the mid-intestine, dietary Zn reduced TAG content, activities of G6PD, ME, isocitrate dehydrogenase and FAS, down-regulated mRNA levels of 6PGD, G6PD, FAS, acetyl-CoA carboxylase a, PPAR $\gamma$ and SREBP-1, but up-regulated mRNA expression of HSLa, ATGL and PPAR $\gamma$. The reduction in TAG content following Zn addition was attributable to reduced lipogenesis and increased lipolysis, and similar regulatory mechanisms were observed between the fore- and mid-intestine.

Key words: Pelteobagrus fulvidraco: Zinc: Intestinal regions: Zinc transport: Lipid metabolism

$\mathrm{Zn}$ is an essential micronutrient for all animals, including fish. It serves important functions in various metabolic pathways, such as transcriptional regulation, protein synthesis and cellular signal recognition ${ }^{(1,2)}$. Dietary $\mathrm{Zn}$ deficiency is associated with anorexia, poor appetite, weight loss and growth retardation ${ }^{(1,3,4)}$. However, $\mathrm{Zn}$ can be toxic at high concentrations $^{(4-6)}$. Thus, as it is an essential but potentially toxic ion, a well-maintained $\mathrm{Zn}$ homoeostasis is crucial for all organisms. Compared to terrestrial animals, fish can absorb $\mathrm{Zn}$ from the diet and water but, at least in freshwater fish, the diet is the main pathway for $\mathrm{Zn}$ absorption ${ }^{(7)}$. Thus, in fish as well as in mammals, regulation of intestinal $\mathrm{Zn}$ absorption is crucial for health and survival ${ }^{(7)}$. Therefore, understanding the mechanisms of intestinal $\mathrm{Zn}$ uptake in fish is of considerable interest from both nutritional and toxicological perspectives. Studies suggested a morpho-functional specialisation of intestinal regions in fish with regard to ion transport ${ }^{(8-10)}$, and fish showed anterior-middle regionalisation of ion transport ${ }^{(11)}$. However, the mechanisms of absorption of mineral elements along the intestinal tract are far less understood ${ }^{(9,12)}$. Highlighting the relative importance of different sections of the intestine in ion transport processes, it is worth exploring the responsiveness of intestinal regionalisation to dietary mineral element addition.

Abbreviations: 6PGD, 6-phosphogluconate dehydrogenase; ACC, acetyl-CoA carboxylase; ATGL, adipose TAG lipase; CPT, carnitine palmitoyltransferase; FAS, fatty acid synthase; G6PD, glucose-6-phosphate dehydrogenase; HSL, hormone-sensitive lipase; ICDH, isocitrate dehydrogenase; ME, malic enzyme; MT, metallothionein; MTF-1, metal response element-binding transcription factor-1; SOD, superoxide dismutase; SREBP, sterol-regulator element-binding protein.

*Corresponding author: Professor Z. Luo, fax +86278728 2114, email luozhi99@mail.hzau.edu.cn; luozhi99@aliyun.com. 
Zn metabolism in higher eukaryotes is complicated, being regulated by a complex interplay of uptake and efflux transporter proteins, coupled with metal-dependent transcriptional control of selected transport and storage proteins ${ }^{(13)}$. Recently, there have been advances in the understanding of genes and proteins involved in these processes and their regulation. ATPases are the membrane-bound enzymes responsible for the transport of ions through a biological membrane ${ }^{(14)}$. Cu-, Znsuperoxide dismutase (SOD) is a $\mathrm{Zn}$-requiring enzyme that represents more than $90 \%$ of the total SOD in cells, and plays important roles in intervening in the first transformation by dismutation of the superoxide free radicals $\left(\mathrm{O}^{2-}\right)$ into $\mathrm{H}_{2} \mathrm{O}_{2}{ }^{(15)}$. The transport of $\mathrm{Zn}$ ions is controlled by two families of ion transporters, the ZnT (solute-linked carrier 30 family, SLC30A/ZnT) and Zips (solute-linked carrier 39 family, SLC39A/ZIP), which function in opposite directions of maintaining cellular $\mathrm{Zn}$ homoeostasis ${ }^{(16,17)}$. The $\mathrm{ZnT}$ proteins, including ZnT1, ZnT5 and ZnT7, play critical roles in maintaining the cytoplasmic $\mathrm{Zn}$ balance by either transporting $\mathrm{Zn}$ out of cells or sequestrating $\mathrm{Zn}$ into intracellular compartments ${ }^{(16-18)}$. By contrast, SLC39 family proteins, including ZIP4 and ZIP5, function to increase the cytosolic $\mathrm{Zn}$ concentration by promoting $\mathrm{Zn}$ import from the extracellular space or $\mathrm{Zn}$ release from organelles ${ }^{(19,20)}$. Metal response element-binding transcription factor-1 (MTF-1) functions as a cellular $\mathrm{Zn}$ sensor that coordinates the expression of genes involved in Zn homoeostasis. Metallothioneins (MT) are small, cysteine-rich, metal-binding proteins that play an important role in $\mathrm{Zn}$ homoeostasis and in detoxification of toxic metals ${ }^{(21)}$. At present, studies on teleost $\mathrm{Zn}$ transporters have been mainly limited to model species because of the limitation of genomic resource in non-model fish species. Recently, Jiang et al. ${ }^{(22)}$ identified a set of thirty-seven $\mathrm{Zn}$ transporters in the common carp genome, including seventeen from the SLC30 family (ZnT) and twenty from SLC39 family (ZIP). However, the underlying molecular mechanisms involved in the regulation of intestinal $\mathrm{Zn}$ transporters in response to dietary $\mathrm{Zn}$ in non-model species remain largely unknown.

In fish, lipids are known to be used as energy reserves, and carry out a vast array of functions. Accordingly, as in mammals, lipid absorption in fish occurs predominantly in the proximal part of the intestine ${ }^{(23)}$. In mammals, studies indicated that $\mathrm{Zn}$ influences lipid metabolism ${ }^{(24,25)}$, indicating a close link between $\mathrm{Zn}$ and lipid metabolism. In general, lipid metabolism results from the balance between synthesis of fatty acids (lipogenesis) and fat catabolism via $\beta$-oxidation (lipolysis), and many key enzymes and transcriptional factors are involved in these metabolic processes. These enzymes include lipogenic enzymes (such as glucose-6-phosphate dehydrogenase (G6PD), 6-phosphogluconate dehydrogenase (6PGD), acetyl-CoA carboxylase (ACC), fatty acid synthase (FAS)) and lipolytic enzymes (such as carnitine palmitoyltransferase I (CPT I), hormone-sensitive lipase (HSL), adipose TAG lipase $(\mathrm{ATGL}))^{(26)}$. In addition, several transcription factors, such as PPAR and sterol-regulator element-binding protein (SREBP-1), play an intermediary role in lipid homoeostasis, by orchestrating the gene transcription of enzymes involved in these pathways ${ }^{(27)}$.
Yellow catfish (Pelteobagrus fulvidraco), an omnivorous freshwater fish, is considered to be a good candidate for freshwater culture in China and other Asian countries because of its delicious meat and high market value. However, excessive lipid deposition in yellow catfish, which may affect the quality of harvest, is a problem. In our laboratory, Zheng et al. ${ }^{(4)}$ found that dietary deficiency and excess of $\mathrm{Zn}$ exerted a profound effect on lipid deposition and metabolism in the liver and muscle of yellow catfish $P$. fulvidraco. In the present study, we hypothesise that there would be regional differences in $\mathrm{Zn}$ transport and lipid metabolism, due to a differential distribution of these specific carriers. Hence, the objectives of the present study were to explore the potential mechanisms of dietary $\mathrm{Zn}$ regulating $\mathrm{Zn}$ metabolism and lipid metabolism in the fore- and mid-intestine in yellow catfish, which provided new insights into $\mathrm{Zn}$ nutrition in fish.

\section{Methods}

The experiment performed on animals followed the ethical guidelines of Huazhong Agricultural University for the care and use of laboratory animals, and the manuscript conformed to the Animal Research Reporting In Vivo Experiments (ARRIVE) Guidelines for Reporting Animal Research.

\section{Diet preparation}

A total of three experimental diets were formulated with $\mathrm{ZnSO}_{4} .7 \mathrm{H}_{2} \mathrm{O}$ supplemented at levels of $0,0.04$ and $0.6 \mathrm{~g} / \mathrm{kg}$ diet at the expense of cellulose (Table 1). Different $\mathrm{Zn}$ contents were added to the diets, based on our previous study ${ }^{(3)}$, in order to produce three different dietary $\mathrm{Zn}$ groups ( $\mathrm{Zn}$ deficiency, adequate $\mathrm{Zn}$ and $\mathrm{Zn}$ excess, respectively). The formulation of the experimental diets was according to Luo et $a l^{(3)}$. The formulated diets were dried at $80^{\circ} \mathrm{C}$ in an oven until the moisture was reduced to $<10 \%$. The dry pellets were

Table 1. Feed formulation and proximate analysis of experimental diets*

\begin{tabular}{lccc}
\hline Ingredients (g/kg) & Zn deficiency & Adequate $\mathrm{Zn}$ & $\mathrm{Zn}$ excess \\
\hline Casein & 360 & 360 & 360 \\
Wheat starch & 250 & 250 & 250 \\
Fish oil & 25 & 25 & 25 \\
Soyabean oil & 50 & 50 & 50 \\
Ascorbyl-2-polyphosphate & 10 & 10 & 10 \\
$\mathrm{NaCl}$ & 10 & 10 & 10 \\
$\mathrm{Ca}\left(\mathrm{H}_{2} \mathrm{PO}_{4}\right)_{2} \cdot \mathrm{H}_{2} \mathrm{O}$ & 10 & 10 & 10 \\
$\mathrm{ZnSO}{ }_{4} \cdot 7 \mathrm{H}_{2} \mathrm{O}$ & 0 & 0.04 & 0.6 \\
Vitamin premix & 5 & 5 & 5 \\
Mineral premix (Zn-free) & 5 & 5 & 5 \\
Betaine & 10 & 10 & 10 \\
Gelatin & 80 & 80 & 80 \\
Cellulose & 185 & 184.96 & 184.4 \\
Proximate analysis (percentage of DM basis) & & \\
$\quad$ Moisture content (\%) & 9.24 & 9.48 & 9.49 \\
Crude protein (\%) & 41.28 & 41.34 & 40.92 \\
Ash (\%) & 2.47 & 2.36 & 2.40 \\
Lipid (\%) & $11 \cdot 18$ & 11.36 & 11.18 \\
Zn (mg/kg) & 8.83 & 19.20 & 146.65 \\
\hline
\end{tabular}

* Vitamin premix according to Luo et al. ${ }^{(3)}$; mineral premix according to Luo et al. ${ }^{(3)}$ without $\mathrm{Zn}$ addition. $\mathrm{ZnSO}_{4} .7 \mathrm{H}_{2} \mathrm{O}(\geq 99.0 \%$ in purity): Sinopharm Chemical Reagent Co. Ltd. 
placed in plastic bags and stored at $-20^{\circ} \mathrm{C}$ until feeding. The final $\mathrm{Zn}$ concentrations in the experimental diets were analysed in triplicate using inductively coupled plasma (ICP) atomic emission spectrometry, and the contents were 8.83 (Zn deficiency), 19.20 (adequate $\mathrm{Zn}$ ) and 146.65 (Zn excess) mg Zn/kg diet, respectively.

\section{Experimental procedures}

The experiment was conducted in Panjin Guanghe Crab Co. Ltd, Panjin, China. Yellow catfish were obtained from a local fish pond (Panjin, China). They were transferred to indoor cylindrical fibreglass tanks ( $90 \mathrm{~cm}$ height, $80 \mathrm{~cm}$ diameter) for 2 weeks of acclimatisation. Afterwards, 216 uniform-sized fish (initial mean weight: 0.81 (SEM 0.01) g) were randomly assigned to nine fibreglass tanks with twenty-four fish per tank. The experiment was conducted in a semi-static aquarium system and continuously aerated to maintain dissolved $\mathrm{O}_{2}$ near saturation. The fish were fed to apparent satiation twice daily with two equal meals (09.00 and 16.00 hours) during the experiment. The amount of feed consumed by the fish in each tank was recorded daily and the dead fish was weighed, and feed intake (FI) and feed conversion rate (FCR)were calculated. $\mathrm{Zn}$ concentrations in water samples collected $10 \mathrm{~min}$ before and after feeding remained very low and negligible throughout the experiment. The experiment was continued for 8 weeks.

The experiment was conducted at ambient temperature and under a natural photoperiod (approximately $12 \mathrm{~h}$ light-12 h dark). Water quality parameters were monitored twice a week in the morning, and the ranges of the parameters were as follows: water temperature, $23 \cdot 1-25 \cdot 0^{\circ} \mathrm{C} ; \mathrm{pH}, 8 \cdot 1-8 \cdot 5$; dissolved $\mathrm{O}_{2} \geq 6.00 \mathrm{mg} / \mathrm{l} ; \mathrm{NH}_{4}-\mathrm{N} \leq 0.06 \mathrm{mg} / \mathrm{l}$.

\section{Sampling}

At the end of the 8-week period, $24 \mathrm{~h}$ after the last feeding, all fish were euthanised (MS-222 at $100 \mathrm{mg} / \mathrm{l}$ ), counted and weighed to determine survival, weight gain (WG) and specific growth rate (SGR). Then, fish were dissected and the contents of the intestine were gently scraped off. The fore-intestine (from the end of the stomach to the first loop of the intestine) and mid-intestine (from the first loop to the last loop) were used for the following analysis. A total of four fish per tank were randomly collected and dissected on ice to obtain the fore- and mid-intestine samples for TAG analysis. For enzyme activity and mRNA expression assays, the fore- and mid-intestine samples of twelve fish from each tank (six fish for enzymatic activities and six fish for mRNA expression) were removed immediately using sterile forceps, frozen in liquid $\mathrm{N}_{2}$ and stored at $-80^{\circ} \mathrm{C}$ (not longer than 2 weeks) for further processing. Remaining samples were stored at $-80^{\circ} \mathrm{C}$ for determining the $\mathrm{Zn}$ content.

\section{Samples analysis}

Enzymatic activity assays. For intestinal lipogenic enzyme analysis, the anterior- and mid-intestine samples were homogenised in three volumes of ice-cold buffer $(0.02 \mathrm{~m}$ TRIS-HCl, $0.25 \mathrm{~m}$ sucrose, $2 \mathrm{~mm}$ EDTA, $0.1 \mathrm{~m}$ sodium fluoride, $0.5 \mathrm{~mm}$ phenylmethyl sulphonyl fluoride and 0.01 M-mercapto-ethanol; $\mathrm{pH} 7.4$ ), and centrifuged at $20000 \mathrm{~g}$ at $4^{\circ} \mathrm{C}$ for $30 \mathrm{~min}$. The supernatant was collected separately, and the activities of five lipogenic enzymes were immediately assayed spectrophotometrically. The reaction was started by addition of the tissue extract. The changes in absorbance at $340 \mathrm{~nm}$ were monitored at intervals of $15 \mathrm{~s}$ for $3 \mathrm{~min}$. 6PGD and G6PD activities were determined by the method of Barroso et al. ${ }^{(28)}$, malic enzyme (ME) activity following Wise \& Ball ${ }^{(29)}$, isocitrate dehydrogenase (ICDH) activity according to Bernt \& Bergmeyer ${ }^{(30)}$, and FAS activity according to the method of Chang et $a l .{ }^{(31)}$ as modified by Chakrabarty \& Leveille ${ }^{(32)}$. TAG content and activities of total ATPase and $\mathrm{Cu}-, \mathrm{Zn}-\mathrm{SOD}$ were determined using a commercial TAG assay Kit (A110-0), ATPase assay kit (A070-1) and a superoxide dismutase typed assay kit (A101-2) (Nanjing Jiancheng Bioengineering Institute), respectively. One unit of enzyme activity (U), defined as the amount of enzyme that converted $1 \mu \mathrm{mol}$ of substrate to product per min at $30^{\circ} \mathrm{C}$, was expressed as units/mg of soluble protein. Soluble protein concentration of homogenates was determined using the method of Bradford ${ }^{(33)}$ with bovine serum albumin as the standard. These analyses were conducted in triplicates.

mRNA expression analysis (real-time fluorescence quantitative $P(R)$. Analyses at the gene-transcript levels were conducted using the real-time quantitative fluorescence PCR (qPCR) method. Frozen tissues were powdered in a liquid $\mathrm{N}_{2}$-chilled mortar and pestle. Total RNA was extracted from tissues using TRIzol Reagent (Invitrogen) based on the acid guanidinium thiocyanate-phenol-chloroform extraction method. A quantity of $2 \mu \mathrm{g}$ of total RNA was used for reverse transcription with RevertAid ${ }^{\mathrm{TM}}$ Reverse Transcriptase (Fermentas) and an oligo-dT primer. qPCR assays were carried out in a quantitative thermal cycler $\left(\mathrm{MyiQ}^{\mathrm{TM}} 2\right.$ Two-Color Real-Time PCR Detection System; Bio-Rad) with a $20 \mu \mathrm{l}$ reaction volume containing $10 \mu \mathrm{l}$ of $2 \times \mathrm{SYBR}^{\circledR}$ Premix Ex Taq ${ }^{\mathrm{TM}}$ (TaKaRa), $0 \cdot 4 \mu \mathrm{l}$ of $10 \mathrm{~mm}$ each of forward and reverse primers, $1 \mu$ liluted complementary DNA (cDNA) template (10-fold), and $8 \cdot 2 \mu \mathrm{l}$ double-distilled $\mathrm{H}_{2} \mathrm{O}$. Primers used for qPCR analysis of genes are given in Table 2 . The qPCR parameters consisted of initial denaturation at $95^{\circ} \mathrm{C}$ for $30 \mathrm{~s}$, followed by forty cycles at $95^{\circ} \mathrm{C}$ for $5 \mathrm{~s}, 57^{\circ} \mathrm{C}$ for $30 \mathrm{~s}$ and $72^{\circ} \mathrm{C}$ for $30 \mathrm{~s}$. All reactions were performed in duplicates and each reaction was verified to contain a single product of the correct size using agarose gel electrophoresis. A non-template control and dissociation curve were performed to ensure that only one PCR product was amplified and that stock solutions were not contaminated. Standard curves were constructed for each gene using serial dilutions of stock cDNA. The relative expression levels were calculated using the $2^{-\Delta \Delta C_{T}}$ method $^{(34)}$ when normalising to the geometric mean of the best combination of two genes as suggested by geNorm ${ }^{(35)}$. Before the analysis, we performed an experiment to check the stability of housekeeping genes ( $\beta$-actin, glyceraldehyde-3-phosphate dehydrogenase (GAPDH), ribosomal protein L7 ( $R P L 7$ ), beta-2-microglobulin (B2M), hypoxanthine-guanine phosphoribosyltransferase (HPRT), TATAbox-binding protein (TBP) and tubulin alpha chain (TUBA)), from which $\beta$-actin and $B 2 M$ showed the most stable level of expression under the experimental conditions. 
Table 2. Primers used for real-time quantitative fluorescence PCR analysis

\begin{tabular}{|c|c|c|c|c|}
\hline Genes & Forward primer $\left(5^{\prime} \rightarrow 3^{\prime}\right)$ & Reverse primer $\left(5^{\prime} \rightarrow 3^{\prime}\right)$ & Size (bp) & Accession no. \\
\hline $6 P G D$ & GCTCTGATGTGGCGAGGTGG & CGTAGAAGGACAGTGCAGTGG & 216 & JX992745 \\
\hline G6PD & CAGGAATGAACGCTGGGATG & TCTGCTACGGTAGGTCAGGTCC & 249 & JX992744 \\
\hline FAS & AACTAAAGGCTGCTGGTTGCTA & САCCTTCCCGTCACAAACCTC & 141 & JN579124 \\
\hline$A C C a$ & GGGGTTTTCACGCTGCTTC & GGTTCTGATTGGGTCGTCCTG & 165 & JX992746 \\
\hline CPT1A & ATTTGAAGAAGCACCCAGAGTATGT & CCCTTTTATGGACGGAGACAGA & 254 & JQ074177 \\
\hline HSLa & GAAGGACAGGACAATGAGAAGC & TGTACCACCAGCCAAGGAGA & 110 & KJ588764 \\
\hline ATGL & TTGCGGAAATGTGATTGAGGT & CACGGAAGGCAGGAGGGA & 291 & KF614123 \\
\hline PPARa & CGAGGATGGGATGCTGGTG & CGTCTGGGTGGTTCGTCTGC & 323 & JX992740 \\
\hline PPARY & ACGCCCCGTTCGTTATCC & TGAGCAGAGTCACCTGGTCATTG & 260 & JX992741 \\
\hline SREBP-1 & CTGGGTCATCGCTTCTTTGTG & TCCTTCGTTGGAGCTTTTGTCT & 188 & JX992742 \\
\hline$Z n T 1$ & CACAAATGCGGATAGTGGGA & GGTCACTTGGAGCAACTGAAAC & 110 & KY652749 \\
\hline ZnT5 & AAGAAAGGACAGAAGGGGACG & ACCAAAGCGGAGCAGTCAAA & 281 & KY652750 \\
\hline ZnT7 & GAACTCCACCTGCTCTTGACC & CCGCCACATCTATCTGAACG & 237 & KY652751 \\
\hline ZIP4 & CATTCATAACTTCGCAGACGG & CCAGAAAGCAACCCCAGATT & 132 & KY652752 \\
\hline ZIP5 & CAGGACAGGGAGATGGTTCAC & GGAAGGACGGCAGACTGATTAC & 327 & KY652753 \\
\hline MT & ATCCTTGCGAGTGCTCCA & GCAGGAATCGCCCTTACAC & 158 & EU124661.1 \\
\hline MTF-1 & CGAGTTGATGTTGCAGAGCC & GAGGTATGGAGGAAAGAAGGGA & 294 & KY652754 \\
\hline$\beta$-Actin & GCACAGTAAAGGCGTTGTGA & ACATCTGCTGGAAGGTGGAC & 136 & EU161066 \\
\hline 18S-rRNA & AGCTCGTAGTTGGATCTCGG & CGGGTATTCAGGCGAGTTTG & 196 & KP938527 \\
\hline RPL7 & GGCAAATGTACAGGAGCGAG & GCCTTGTTGAGCTTGACGAA & 199 & KP938522 \\
\hline$B 2 M$ & GCTGATCTGCCATGTGAGTG & TGTCTGACACTGCAGCTGTA & 186 & KP938520 \\
\hline HPRT & ATGCTTCTGACCTGGAACGT & TTGCGGTTCAGTGCTTTGAT & 181 & KP938523 \\
\hline UBCE & TCAAGAAGAGCCAGTGGAGG & TAGGGGTAGTCGATGGGGAA & 150 & KP938524 \\
\hline TUBA & TCAAAGCTGGAGTTCTCGGT & AATGGCCTCGTTATCCACCA & 135 & KP938526 \\
\hline
\end{tabular}

6PGD, 6-phosphogluconate dehydrogenase; G6PD, glucose-6-phosphate dehydrogenase; $F A S$, fatty acid synthase; $A C C$, acetyl-CoA carboxylase; CPT I, carnitine palmitoyltransferase I; HSL, hormone-sensitive lipase; $A T G L$, adipose TAG lipase; SREBP-1, sterol-regulator element-binding protein; $M T$, metallothionein; MTF-1, metal response element-binding transcription factor-1; RPL7, ribosomal protein L7; B2M, beta-2-microglobulin; $H P R T$, hypoxanthine-guanine phosphoribosyltransferase; UBCE, ubiquitin-conjugating enzyme; TUBA, tubulin alpha chain.

Zinc content. For the determination of $\mathrm{Zn}$ content, the fore- and mid-intestinal samples were digested in $3 \mathrm{ml}$ concentrated nitric acid at $110^{\circ} \mathrm{C}$ for $72 \mathrm{~h}$, and diluted to appropriate concentrations for $\mathrm{Zn}$ content using ICP-MS ${ }^{(36)}$. Quality assurance/quality control procedures included analysis of three method blanks (purified water), two certified biological reference tissues (DORM-2 and DORM-4; National Research Council of Canada) and two randomly selected duplicate samples per twenty samples. Recovery of $\mathrm{Zn}$ from certified biological reference tissues mentioned above ranged from 95 to $102 \%$.

\section{Calculations}

SR $($ survival rate $)=(100 \times($ final fish number $) /($ initial fish number $))$

$\mathrm{WG}($ weight gain $)=((\mathrm{FBW}-\mathrm{IBW}) / \mathrm{IBW}) \times 100 \%$

SGR $($ specific growth rate, $\% / d)=(100 \times(\ln (\mathrm{FBW})-\ln (\mathrm{IBW})) / \mathrm{d})$

FCR $(\%)=$ feed intake $/($ FBW - IBW + dead fish weight $), g)$.

\section{Statistical analysis}

The results were presented as means with their standard errors . Before statistical analysis, all data were tested for normality of distribution using the Kolmogorov-Smirnov test. Then, data from each treatment were subjected to one-way ANOVA. When overall differences were significant $(P<0 \cdot 05)$, Duncan's multiple range test was used to compare significant differences between the treatments. Statistical analysis was performed using SPSS 19.0 for Windows.
Table 3. Effect of dietary zinc levels on growth performance of yellow catfish after 8 weeks

(Mean values with their standard errors; $n 3$ replicate tanks, five fish were sampled for each tank)

\begin{tabular}{|c|c|c|c|c|c|c|}
\hline & \multicolumn{6}{|c|}{ Diets } \\
\hline & \multicolumn{2}{|c|}{ Zn deficiency } & \multicolumn{2}{|c|}{ Adequate $\mathrm{Zn}$} & \multicolumn{2}{|c|}{ Zn excess } \\
\hline & Mean & SEM & Mean & SEM & Mean & SEM \\
\hline IBW & 0.80 & 0.02 & 0.80 & 0.03 & 0.83 & 0.01 \\
\hline FBW & 1.90 & 0.03 & 2.05 & 0.08 & 1.94 & 0.03 \\
\hline WG & $138.4^{\mathrm{a}}$ & $6 \cdot 1$ & $155 \cdot 2^{\mathrm{b}}$ & 3.0 & $143 \cdot 8^{a, b}$ & 4.1 \\
\hline SGR & $1.73^{\mathrm{a}}$ & 0.05 & $1.87^{\mathrm{b}}$ & 0.02 & $1.71^{\mathrm{a}, \mathrm{b}}$ & 0.02 \\
\hline $\mathrm{FI}$ & $2 \cdot 05$ & 0.04 & $2 \cdot 17$ & 0.06 & $2 \cdot 16$ & 0.06 \\
\hline FCR & 1.71 & 0.05 & 1.67 & 0.09 & 1.74 & 0.09 \\
\hline SR & $92 \cdot 22$ & $1 \cdot 11$ & 94.45 & $2 \cdot 22$ & $91 \cdot 11$ & $2 \cdot 22$ \\
\hline
\end{tabular}

IBW, initial mean body weight; FBW, final mean body weight; WG, weight gain; SGR, specific growth rate; $\mathrm{FI}$, feed intake; FCR, feed conversion rate; SR, survival rate. ${ }^{a, b}$ Mean values with unlike superscript letters were significantly different between the different dietary $\mathrm{Zn}$ groups $(P<0.05)$.

Results

Growth performance

WG and SGR were numerically the highest in the adequate-Zn group but showed no significant differences between the other two groups (Table 3). FI, FCR and survival showed no significant differences between the three treatments.

\section{Zinc and TAG contents in the intestine}

In the fore-intestine and mid-intestine, $\mathrm{Zn}$ contents increased with increasing dietary $\mathrm{Zn}$ levels (Fig. 1(A)). In contrast, TAG 
(A)

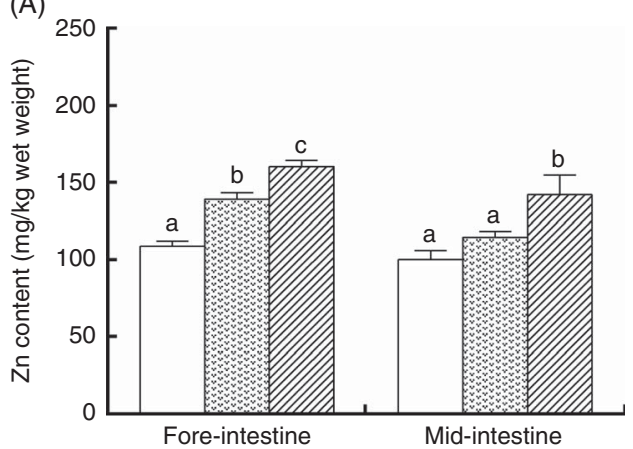

(B)

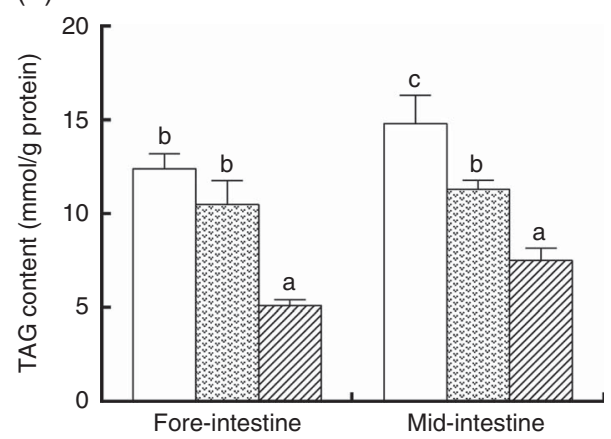

Fig. 1. Effect of dietary zinc levels on zinc (A) and TAG (B) contents in the intestine of yellow catfish. Values are means ( $n 3$ replicate tanks), with standard errors represented by vertical bars. For zinc content analysis, four to six fish sampled for each tank; for TAG content, four fish were sampled for each tank. $\square$, Zinc deficiency;

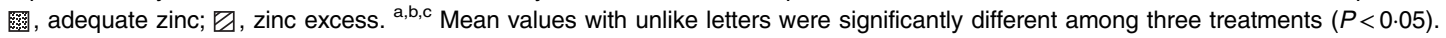

(A)

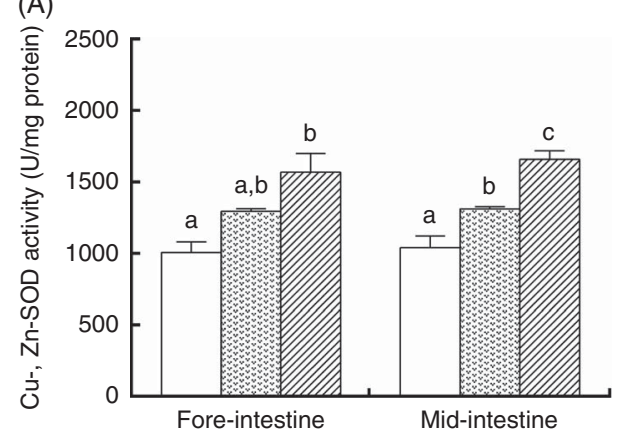

(B)

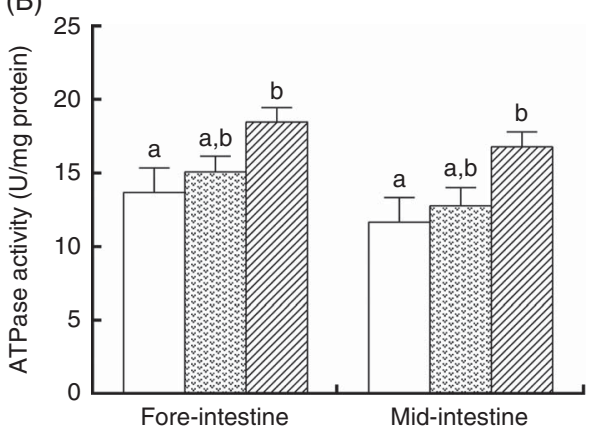

Fig. 2. Effect of dietary zinc levels on Cu-, Zn-superoxide dismutase (SOD) (A) and ATPase (B) activities in the intestine of yellow catfish. Values are means ( $n 3$ replicate tanks, 6 fish were sampled for each tank), with standard errors represented by vertical bars. $\square$, Zinc deficiency; 图, adequate zinc; $\square$, zinc excess. a,b,c Mean values with unlike letters were significantly different between the three treatments $(P<0.05)$.

contents in the fore-intestine and mid-intestine decreased with increasing dietary Zn levels (Fig. 1(B)).

\section{Activities of intestinal enzymes involved in zinc transport}

In the fore-intestine and mid-intestine, Cu-, $\mathrm{Zn}$-SOD and total ATPase activities increased with increasing dietary $\mathrm{Zn}$ levels (Fig. 2).

\section{mRNA expression levels of genes involved in zinc metabolism}

In the fore-intestine, mRNA levels of ZnT1, ZnT5, ZnT7, MT and MTF-1 tended to increase with increasing dietary $Z n$ levels (Fig. 3(A)). mRNA levels of ZnT1, ZnT5, ZnT7, MT and MTF-1 in the $Z n$-excess group were the highest and were significantly higher than those in the other two groups. By contrast, ZIP5 mRNA levels declined with increasing dietary Zn levels. ZIP4 and ZIP5 mRNA levels were the lowest for fish fed the Zn-excess diet and showed no significant difference between the other two groups.

In the mid-intestine, dietary $\mathrm{Zn}$ addition up-regulated mRNA levels of ZnT1, ZnT5 and ZnT7 (Fig. 3(B)). mRNA levels of ZnT5 and ZnT7 in the Zn-excess group were the highest and were significantly higher than those in the other two groups.
mRNA levels of ZIP4 and ZIP5 were the lowest for fish fed the Zn-excess diet and showed no significant differences between the other two groups. ZnT1, MT and MTF-1 mRNA levels were the highest for fish fed the Zn-excess diet and showed no significant differences between the other two groups.

\section{Intestinal lipogenic enzyme activities}

In the fore-intestine, 6PGD, ME and FAS activities tended to decrease with increasing dietary Zn levels (Fig. 4(A)). G6PD activity in the Zn-deficiency group was significantly higher than that of the adequate- and excess-Zn groups. ICDH activity was the highest for fish fed the adequate- $Z n$ diet and showed no significant differences between the other two groups. FAS activity in the Zn-excess group was the lowest and was significantly lower than that in the other two groups.

In the mid-intestine, G6PD and ME activities tended to decrease with increasing dietary $\mathrm{Zn}$ levels (Fig. 4(B)). G6PD and $\mathrm{ME}$ activities in the Zn-deficiency group was the highest and was significantly higher than that of the adequate- and excess- $\mathrm{Zn}$ groups. ICDH activity in the Zn-excess group was the lowest and it showed no significant difference between the adequate- $Z n$ and $Z n$-deficiency groups. FAS activities were the highest in the Zn-deficiency group and they showed no significant differences between the other two groups. 6PGD showed no significant differences between the three treatments. 

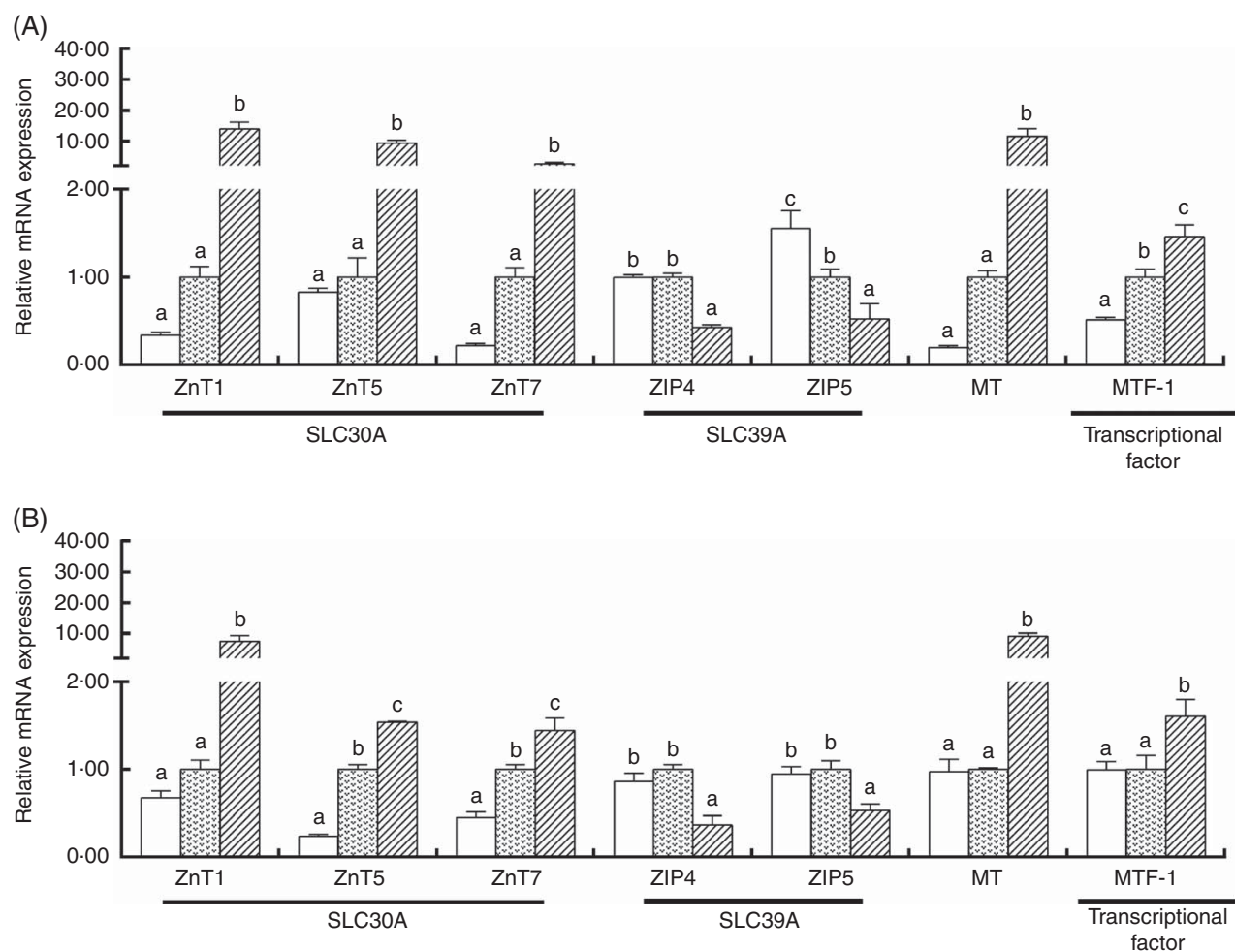

Fig. 3. Effect of dietary zinc levels on the mRNA levels of genes involved in zinc metabolism in the fore-intestine (A) and mid-intestine (B) of yellow catfish. Values are means ( $n 3$ replicate tanks, 6 fish were sampled for each tank), with standard errors represented by vertical bars. $\square$, Zinc deficiency; 图, adequate zinc; $\oslash$, zinc excess; MT, metallothioneins; MTF-1, metal response element-binding transcription factor-1. mRNA expression values were normalised to $\beta$-actin and beta-2microglobulin $(B 2 M)$ expressed as a ratio of the control (control $=1)$. ${ }^{a, b, c}$ Mean values with unlike letters were significantly different between the three treatments $(P<0.05)$.
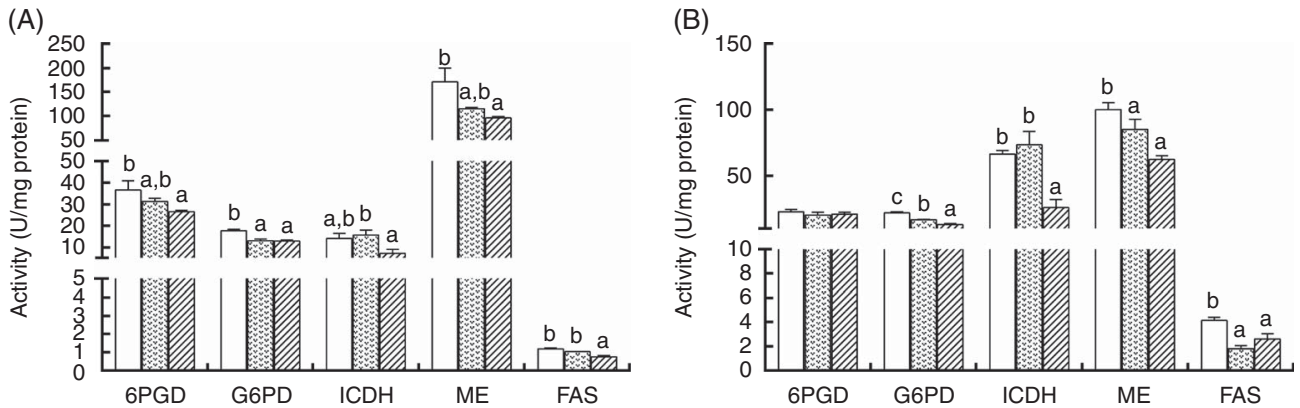

Fig. 4. Effect of dietary zinc levels on enzyme activities involved in lipid metabolism in the fore-intestine (A) and mid-intestine (B) of yellow catfish. Values are means ( $n 3$ replicate tanks, 6 fish were sampled for each tank), with standard errors represented by vertical bars. $\square$, Zinc deficiency; 畻, adequate zinc; $\square$, zinc excess; 6PGD, 6-phosphogluconate dehydrogenase; G6PD, glucose-6-phosphate dehydrogenase; ME, malic enzyme; ICDH, isocitrate dehydrogenase; FAS, fatty acid synthase. ${ }^{a, b, c}$ Mean values with unlike letters were significantly different between the three treatments $(P<0.05)$.

\section{mRNA expression levels of genes involved in lipid metabolism}

In the fore-intestine, mRNA levels of G6PD and FAS tended to decline, but mRNA levels of CPT IA and HSLa tended to increase with increasing dietary Zn levels (Fig. 5(A)). mRNA levels of G6PD, 6PGD, FAS and ACCa in the Zn-excess group were significantly lower than those of the adequate- $Z n$ and Zn-deficiency groups. CPT IA, HSLa and ATGL mRNA levels for fish fed the Zn-deficient diet were significantly lower than those of the adequate- and excess-Zn groups. PPAR $\alpha$ mRNA levels were the highest for fish fed the $\mathrm{Zn}$-excess diet, and showed no significant differences between the other two groups. mRNA levels of PPAR $\gamma$ and SREBP-1 were the highest for fish fed the Zn-deficient diet and showed no significant differences between the other two groups.

In the mid-intestine, dietary $\mathrm{Zn}$ addition tended to downregulate mRNA levels of 6PGD, FAS, ACCa, PPAR $\gamma$ and SREBP-1, but to up-regulate the mRNA expression of HSLa and ATGL (Fig. 5(B)). mRNA levels of G6PD, 6PGD and FAS in the Zn-excess group were significantly lower than those of the adequate-Zn and Zn-deficiency groups. ACCa mRNA level in the Zn-deficiency group was significantly higher than that in the other two groups. The highest PPAR $\alpha$ expression was observed for fish fed the Zn-excess diet and showed no significant differences between other two groups. CPT IA mRNA levels 

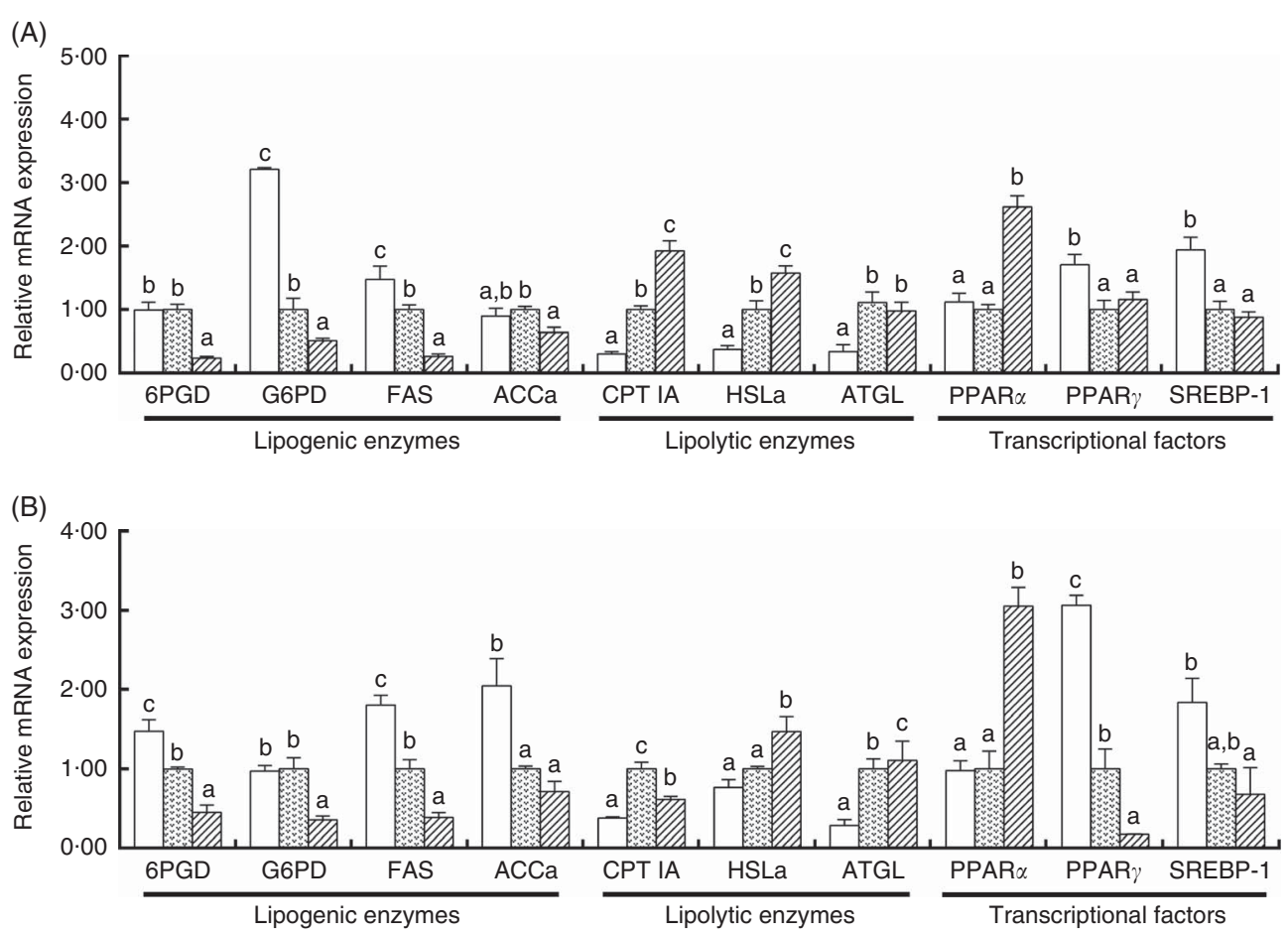

Fig. 5. Effect of dietary zinc levels on the mRNA levels of genes involved in lipid metabolism in the fore-intestine (A) and mid-intestine (B) of yellow catfish. Values are means ( $n 3$ replicate tanks, 6 fish were sampled for each tank), with standard errors represented by vertical bars. $\square$, Zinc deficiency; 圈, adequate zinc; $\square$, zinc excess; 6PGD, 6-phosphogluconate dehydrogenase; G6PD, glucose-6-phosphate dehydrogenase; FAS, fatty acid synthase; ACCa, ACC, acetyl-CoA carboxylase; CPT I, carnitine palmitoyltransferase I; HSL, hormone-sensitive lipase; ATGL, adipose TAG lipase; SREBP-1, sterol-regulator element-binding protein. mRNA expression values were normalised to $\beta$-actin and beta-2-microglobulin $(B 2 M)$ expressed as a ratio of the control $($ control $=1)$. ${ }^{a, b, c}$ Mean values with unlike letters were significantly different between the three treatments $(P<0 \cdot 05)$.

were the highest for fish fed the adequate- $\mathrm{Zn}$ diet and lowest in the Zn-deficient group. PPAR $\gamma$ mRNA level for fish fed the Zn-deficient diet was significantly higher than that of the adequate-Zn and Zn-deficiency groups. SREBP-1 mRNA level was the highest for fish fed the Zn-deficient diet, but showed no significant differences between the other two groups.

\section{Discussion}

Previous studies in yellow catfish have focused on the changes in lipid deposition and metabolism in the liver, muscle and adipose tissue ${ }^{(5,37,38)}$, and lipid metabolism in the intestine has been neglected. To our knowledge, this is the first study aimed at deducing the basic mechanisms of intestinal lipid metabolism in combination with $\mathrm{Zn}$ transport in a fish species.

In the present study, dietary $\mathrm{Zn}$ addition induced intestinal $\mathrm{Zn}$ accumulation, in agreement with other reports ${ }^{(39,40)}$. To explore the mechanism of $\mathrm{Zn}$ absorption and accumulation, we analysed the activities of enzymes and/or the mRNA expression of genes involved in $\mathrm{Zn}$ metabolism. Our results indicated that dietary $\mathrm{Zn}$ addition tended to increase total ATPase and Cu-, ZnSOD activities. The increases in ATPase activity could possibly occur because of the maintenance of the ion flux ${ }^{(41)}$. Kavitha \& $\mathrm{RaO}^{(42)}$ suggested that the induction in antioxidant enzymatic activities could be an adaptive response to toxicant stress and to neutralise the impact of ROS generated. The report demonstrated that dietary $\mathrm{Zn}$ excess up-regulated mRNA levels of
ZnT1, ZnT5 and ZnT7, but down-regulated mRNA levels of ZIP4 and ZIP5 in the fore-intestine and mid-intestine. ZnT proteins are characterised by their ability to decrease the cytosolic $\mathrm{Zn}$ concentration by transporting $\mathrm{Zn}$ out of cells or into intracellular compartments ${ }^{(43)}$. In mammals and in zebrafish, dietary $\mathrm{Zn}$ regulates $\mathrm{Zn}$-transport activities and $\mathrm{Zn}$-transporter gene expression in the intestine ${ }^{(2,44)}$. Studies reported the up-regulation of mRNA levels of $\mathrm{ZnT}^{(44,45)}$, which, in turn, reduced cytosolic Zn availability ${ }^{(19)}$. ZnT5 and ZnT7 are localised on the membrane of the Golgi apparatus as well as the cytoplasmic vesicles, and these transporters have been shown to transport $\mathrm{Zn}$ into the secretory pathway for $\mathrm{Zn}$ sequestration and/or Zn supply to the proteins that require $\mathrm{Zn}$ for structural formation or activities ${ }^{(17,43)}$. Thus, increased ZnT5 and ZnT7 mRNA expression will increase the transport of $\mathrm{Zn}$ from the cytosol into the secretory pathway for $\mathrm{Zn}$ sequestration and, accordingly, reduce $\mathrm{Zn}$ toxicity. These regulatory patterns would be consistent with functions of the corresponding proteins in $\mathrm{Zn}$ efflux from the cytosol, and reflect the need for greater $\mathrm{Zn}$-export capacity from the cytosol, which helps delay intracellular $\mathrm{Zn}$ toxicity in the intestine. The present study indicated that dietary $\mathrm{Zn}$ addition down-regulated mRNA levels of ZIP4 and ZIP5 in the fore-intestine and mid-intestine. Increased ZIP4 mRNA expression results in increased dietary $\mathrm{Zn}$ absorption in response to $\mathrm{Zn}$ restriction, as suggested by several studies $^{(16,46)}$. Kambe et al. ${ }^{(6)}$ pointed out that ZIP5 was functional as a Zn importer and ZIP5 expression decreased in $\mathrm{Zn}$-depleted environments. Taken together, these changes 
suggested that the fractional $\mathrm{Zn}$ absorbed from the diet decreased and the export of $\mathrm{Zn}$ from the intestinal epithelium increased as dietary $\mathrm{Zn}$ load increased, indicating the presence of a mechanism for regulating the metabolism of dietary $\mathrm{Zn}$. Our result showed that MT mRNA levels in the fore-intestine and mid-intestine were up-regulated when fish were fed with excessive dietary $\mathrm{Zn}$, in agreement with many other studies $^{(2,45,47)}$. In the present study, dietary $\mathrm{Zn}$ excess induced the up-regulation of MTF- 1 mRNA level in the fore-intestine and mid-intestine, together with the up-regulation of ZnT1 and MT gene expression. MTF-1 is important for the induction of ZnT1 and MT expression by Zn, via binding to multiple metalresponsive elements in the $5^{\prime}$ regulatory regions of their respective genes' promoter ${ }^{(47,48)}$. The activation of MTF-1 in response to $\mathrm{Zn}$ parallels increases in the relative rate of transcription of MT-1 and $\mathrm{ZnT}^{(45,48,49)}$. Thus, these results reported, generally, similar rates in fore- and mid-intestinal segments, which was not surprising in view of the fact that activities and gene expression related to $\mathrm{Zn}$ uptake and transport were similar in the two segments, although exceptions had been reported.

The present study indicated that, in the fore-intestine, dietary $Z n$ addition reduces TAG content, activities of 6PGD, G6PD, ME and FAS as well as down-regulated mRNA levels of 6PGD, G6PD and FAS. G6PD, 6PGD, ICDH, ME and FAS are the key regulatory enzymes and genes involved in lipogenesis ${ }^{(26)}$. The reduction in activities of lipogenic enzymes (6PGD, G6PD, ME and FAS) and gene expression (6PGD, G6PD and FAS) in response to dietary $\mathrm{Zn}$ addition would contribute to the reduced TAG content. Similarly, Eder \& Kirchgessner ${ }^{(50)}$ reported that dietary Zn-deficiency increased the activities of lipogenic enzymes (6PGD and G6PD) in rats. Our study also found that the changes in activities of FAS, 6PGD and G6PD were in parallel with the changes of their mRNA expression, suggesting that these enzymes were regulated by $\mathrm{Zn}$ at the transcriptional level. CPT I, HSLa and ATGL are three key genes involved in lipolysis ${ }^{(51,52)}$. The present study indicated that dietary $\mathrm{Zn}$ addition up-regulated mRNA levels of CPT IA, HSLa and ATGL in the fore-intestine. The up-regulation of these lipolytic enzymatic genes following dietary $\mathrm{Zn}$ addition would increase lipolysis, which, in turn, would reduce TAG content, as observed in the present study. Similarly, Zheng et al. ${ }^{(4)}$ found that hepatic lipid contents declined with increasing dietary $\mathrm{Zn}$ levels, in parallel with increasing mRNA levels of CPT IA, G6PD and 6PGD, and reduced mRNA levels of ACCa and FAS, in yellow catfish. Our study indicated that, in the mid-intestine, dietary $\mathrm{Zn}$ addition reduced TAG contents, activities of G6PD, ME, FAS and ICDH and mRNA levels of 6PGD, G6PD, FAS and ACCa, but up-regulated mRNA levels of HSLa, ATGL and CPT IA. Thus, our study clearly suggested that dietary Zn supplementation decreased TAG content by up-regulating lipolysis and down-regulating lipogenesis in the mid-intestine of yellow catfish. We also found that changes in 6PGD activity in the midintestine were not attributable to the change of its mRNA expression. Similarly, enzymatic activities were not always accompanied by parallel changes in mRNA levels ${ }^{(53)}$. The mismatch between gene expression and enzyme-protein level may be involved in the time-lag effect between transcription and translation and/or RNA stability ${ }^{(54)}$. On the other hand, our observations reveal the similar mRNA expression of genes involved in lipid metabolism between the fore- intestine and mid-intestine after diet-borne $\mathrm{Zn}$ exposure, indicating a similar regulatory mechanism in $\mathrm{Zn}$-induced changes of lipid metabolism between the fore- and mid-intestine of yellow catfish.

It is well documented that expression patterns of lipid metabolic pathway genes are, primarily, governed by SREBP-1 and $\operatorname{PPAR}^{(27,55)}$. The present study indicated that dietary $\mathrm{Zn}$ addition up-regulated PPAR $\alpha$ mRNA levels, but down-regulated mRNA levels of PPAR $\gamma$ and SREBP-1 in the fore-intestine. PPAR $\alpha$ plays key roles in the catabolism of fatty acids by increasing the expression of key lipolytic enzymes ${ }^{(56)}$. In the fore-intestine, the up-regulation of $\operatorname{PPAR} \alpha$, together with the increase in the transcriptional levels of lipolytic genes CPT IA, HSLa and ATGL, might contribute to the reduction of TAG content by Zn-added diets, which resulted in reduced TAG content in the foreintestine. Similarly, Zheng et $a l^{(4)}$ indicated that the mRNA expression of $\operatorname{PPAR} \alpha$ was significantly reduced during $\mathrm{Zn}$ deficiency and that this effect was reversible by $\mathrm{Zn}$ supplementation. SREBP-1 and PPAR $\gamma$ activate genes involved in lipogenesis ${ }^{(57,58)}$. SREBP-1 and PPAR $\gamma$ mediated TAG synthesis and accumulation by the regulation of genes involved in lipogenesis at the transcriptional level ${ }^{(59)}$. Thus, the reduction in TAG deposition in the fore-intestine by $\mathrm{Zn}$ addition might be explained by the suppression of both SREBP-1 and PPAR $\gamma$, together with the concomitant reduction in the activities of lipogenic enzymes 6PGD, G6PD, ME and FAS, and mRNA levels of 6PGD, G6PD and FAS. Shen et al. ${ }^{(60)}$ pointed out that the expression of PPAR $\gamma$ was significantly reduced during $\mathrm{Zn}$ deficiency. Amemiya-Kudo et al. ${ }^{(57)}$ suggested that SREBP-1 positively regulated ACC through binding to regulatory sequences in the promoter, and subsequently enhanced the transcription level. By contrast, Zheng et al. ${ }^{(4)}$ found that mRNA levels of PPAR $\alpha$ and SREBP-1 increased, but PPAR $\gamma$ mRNA levels reduced in the liver with increasing dietary $\mathrm{Zn}$ levels. In the mid-intestine, dietary $\mathrm{Zn}$ addition tended to down-regulate mRNA levels of PPAR and SREBP-1, in parallel with the reduced activities of G6PD, ME, FAS and ICDH, and mRNA levels of 6PGD, G6PD, FAS, ACCa. Thus, the present study indicated that $\operatorname{PPAR} \alpha, \operatorname{PPAR} \gamma$ and SREBP-1 mediated the regulation of lipid deposition and metabolism in the fore- and mid-intestine in yellow catfish. Similarly, several studies reported that these signalling pathways widely mediated mineral element-induced changes in hepatic lipid deposition in fish ${ }^{(36,38)}$.

In conclusion, dietary $\mathrm{Zn}$ supplementation increased $\mathrm{Zn}$ accumulation but reduced TAG content in both the fore- and mid-intestine of yellow catfish. Increased $\mathrm{Zn}$ accumulation was attributable to the changes in enzymatic activities and mRNA expression of genes involved in $\mathrm{Zn}$ absorption and transportation. The reduced TAG content in both the fore- and midintestine of yellow catfish were attributable to the up-regulated lipolysis and down-regulated lipogenesis. Our observations also revealed the similar mRNA expression of genes involved in $\mathrm{Zn}$ and lipid metabolism between the fore- and mid-intestine after dietary $\mathrm{Zn}$ addition, indicating presence of the same or similar regulatory mechanisms of $\mathrm{Zn}$ and lipid metabolism in the foreand mid-intestine of yellow catfish. 


\section{Acknowledgements}

This work was supported by the National Natural Science Foundation of China (grant no. 31422056).

Contributions of authors are as follows: Z. L. and G.-H. C. designed the experiment and analysed the data; G.-H. C. conducted the feeding trial, sample analysis and drafted the article; D.-G. Z. and S.-C. L. assisted with conducting the feeding trial and sample analysis; K. W. helped with analysis of gene expression and enzymatic activities; Z. L. and C. H. revised the manuscript; all authors read and approved the final paper.

The authors declare that there are no conflicts of interest.

\section{References}

1. Watanabe T, Kiron V \& Satoh S (1997) Trace minerals in fish nutrition. Aquaculture 151, 185-207.

2. Zheng D, Feeney GP, Kille P, et al. (2008) Regulation of ZIP and $\mathrm{ZnT}$ zinc transporters in zebrafish gill: zinc repression of ZIP10 transcription by an intronic MRE cluster. Physiol Genomics 34, 205-214.

3. Luo Z, Tan XY, Zheng JL, et al. (2011) Quantitative dietary zinc requirement of juvenile yellow catfish Pelteobagrus fulvidraco, and effects on hepatic intermediary metabolism and antioxidant responses. Aquaculture 319, 150-155.

4. Zheng JL, Luo Z, Hu W, et al. (2015) Different effects of dietary Zn deficiency and excess on lipid metabolism in yellow catfish Pelteobagrus fulvidraco. Aquaculture 435, 10-17.

5. Hogstrand C \& Wood CM (1996) The physiology and toxicology of zinc. In Fish Toxicology of Aquatic Pollution, pp. 61-84 [EW Taylor, editor]. Cambridge: Cambridge University Press.

6. Kambe T, Tsuji T, Hashimoto A, et al. (2015) The physiological, biochemical, and molecular roles of zinc transporters in zinc homeostasis and metabolism. Physiol Rev 95, 749-784.

7. Bury NR, Walker PA \& Glover CN (2003) Nutritive metal uptake in teleost fish. J Exp Biol 206, 11-23.

8. Ojo AA \& Wood CM (2008) In vitro characterization of cadmium and zinc uptake via the gastro-intestinal tract of the rainbow trout (Oncorbynchus mykiss): interactive effects and the influence of calcium. Aquat Toxicol 89, 55-64.

9. Klinck JS \& Wood CM (2011) In vitro characterization of cadmium transport along the gastro-intestinal tract of freshwater rainbow trout (Oncorbynchus mykiss). Aquat Toxicol 102, 5-72.

10. Ruhr IM, Takei Y \& Grosell M (2016) The role of the rectum in osmoregulation and the potential effect of renoguanylin on SLC26a6 transport activity in the Gulf toadfish (Opsanus beta). Am J Physiol Regul Integr Comp Physiol 311, R179-R191.

11. Ruiz-Jarabo I, Gregorio SF, Gaetano P, et al. (2017) High rates of intestinal bicarbonate secretion in seawater tilapia (Oreochromis mossambicus). Comp Biochem Physiol A Mol Integr Physiol 207, 57-64.

12. Ojo AA \& Wood CM (2007) In vitro analysis of the bioavailability of six metals via the gastro-intestinal tract of the rainbow trout (Oncorbynchus mykiss). Aquat. Toxicol 83, 10-23.

13. Laity JH \& Andrews GK (2007) Understanding the mechanisms of zinc-sensing by metal-response element binding transcription factor-1 (MTF-1). Arch Biochem Biophys 463, 201-210.

14. Marshall WS \& Grosell M (2006) Ion transport, osmoregulation and acid-base balance. Physiol Fish 3, 177-230.

15. Wang G, Liu X, Guo Q, et al. (2010) Chronic treatment with fibrates elevates superoxide dismutase in adult mouse brain microvessels. Brain Res 1359, 247-255.
16. Liuzzi JP \& Cousins RJ (2004) Mammalian zinc transporters. Annu Rev Nutr 24, 151-172.

17. Huang L \& Tepaamorndech S (2013) The SLC30 family of zinc transporters - a review of current understanding of their biological and pathophysiological roles. Mol Aspects Med 34, 548-560.

18. Palmiter RD (2004) Protection against zinc toxicity by metallothionein and zinc transporter 1. Proc Natl Acad Sci USA 101, 4918-4923.

19. Dufner-Beattie J, Kuo YM, Gitschier J, et al. (2004) The adaptive response to dietary zinc in mice involves the differential cellular localization and zinc regulation of the zinc transporters ZIP4 and ZIP5. J Biol Chem 279, 49082-49090.

20. Geiser J, De Lisle RC \& Andrews GK (2013) The zinc transporter Zip5 (Slc39a5) regulates intestinal zinc excretion and protects the pancreas against zinc toxicity. PLOS ONE $\mathbf{8}$, e82149.

21. Davis SR \& Cousins RJ (2000) Metallothionein expression in animals: a physiological perspective on function. J Nutr 130, $1085-1088$.

22. Jiang Y, Zhang S, Feng S, et al. (2014) Genome wide identification, phylogeny and expression of zinc transporter genes in common carp. PLOS ONE 9, e116043.

23. Tocher DR (2003) Metabolism and functions of lipids and fatty acids in teleost fish. Rev Fish Sci 11, 107-184.

24. Cunnane SC (1987) Role of zinc in lipid and fatty acid metabolism and in membranes. Prog Food Nutr Sci 12, 151-188.

25. Huang L, Yu YY, Kirschke CP, et al. (2007) Znt7 (Slc30a7)deficient mice display reduced body zinc status and body fat accumulation. J Biol Chem 282, 37053-37063.

26. Elliott WH \& Elliott DC (2009) Biochemistry and Molecular Biology, 4th ed. Oxford: Oxford University.

27. Spiegelman BM \& Flier JS (2001) Obesity and the regulation of energy balance. Cell 104, 531-543.

28. Barroso JB, Peragón J, Garcia-Salguero L, et al. (1999) Variations in the kinetic behaviour of the NADPH-production systems in different tissues of the trout when fed on an aminoacid-based diet at different frequencies. Int J Biochem Cell Biol 31, 277-290.

29. Wise EM \& Ball EG (1964) Malic enzyme and lipogenesis. Proc Natl Acad Sci U S A 52, 1255-1263.

30. Bernt E \& Bergmeyer HU (1974) Isocitrate dehydrogenase. In Methods of Enzymatic Analysis vol. 2, pp. 624-627 [Bergmeyer, HU, editor]. New York: Academic Press.

31. Chang HC, Seidman I, Teebor G, et al. (1967) Liver acetyl CoA carboxylase and fatty acid synthetase: relative activities in the normal state and in hereditary obesity. Biochem Biophys Res Commun 28, 682-686.

32. Chakrabarty K \& Leveille GA (1969) Acetyl CoA carboxylase and fatty acid synthetase activities in liver and adipose tissue of meal-fed rats. Proc Soc Exp Biol Med 131, 1051-1054.

33. Bradford MM (1976) A rapid and sensitive method for the quantitation of microgram quantities of protein utilizing the principle of protein-dye binding. Anal Biochem 72, 248-254.

34. Livak KJ \& Schmittgen TD (2001) Analysis of relative gene expression data using realtime quantitative PCR and the $2^{-\Delta \Delta \mathrm{CT}}$ method. Methods 25, 402-408.

35. Vandesompele J, De Preter K, Pattyn F, et al. (2002) Accurate normalization of real-time quantitative RT-PCR data by geometric averaging of multiple internal control genes. Genome Biol 3, 1-12.

36. Chen GH, Luo Z, Chen F, et al. (2017) PPAR $\alpha$, PPAR $\gamma$ and SREBP-1 pathways mediated waterborne iron (Fe)-induced reduction in hepatic lipid deposition of javelin goby Synechogobius hasta. Comp Biochem Physiol C Toxicol Pharmacol 197, 8-18. 
37. Zheng JL, Luo Z, Zhuo MQ, et al. (2014) Dietary L-carnitine supplementation increases lipid deposition in the liver and muscle of yellow catfish (Pelteobagrus fulvidraco) through changes in lipid metabolism. Br J Nutr 112, 698-708.

38. Wei CC, Wu K, Gao Y, et al. (2017) Magnesium reduces hepatic lipid accumulation in yellow catfish (Pelteobagrus fulvidraco) and modulates lipogenesis and lipolysis via PPARA, JAK-STAT and AMPK pathways in hepatocytes. J Nutr 147, 1070-1078.

39. Glover $\mathrm{CN} \&$ Hogstrand C (2002) In vivo characterisation of intestinal zinc uptake in freshwater rainbow trout. $J$ Exp Biol 205, 141-150.

40. Feng L, Tan LN, Liu Y, et al. (2011) Influence of dietary zinc on lipid peroxidation, protein oxidation and antioxidant defence of juvenile jian carp (cyprinus carpio, var. jian). Aquac Nutr 17, e875-e882.

41. Eroglu A \& Canli M (2013) Effects of $\mathrm{Cd}, \mathrm{Zn}$ and $\mathrm{Cd}+\mathrm{Zn}$ combination on ATPase activity in the gill and muscle of tilapia (Oreochromis niloticus). Bull Environ Contam Toxicol 91, 420-425.

42. Kavitha P \& Rao JV (2009) Sub-lethal effects of profenofos on tissue-specific antioxidative responses in a Euryhaline fish, Oreochromis mossambicus. Ecotoxicol Environ Saf 72, $1727-1733$.

43. Kirschke CP \& Huang L (2003) ZnT7, a novel mammalian zinc transporter, accumulates zinc in the Golgi apparatus. $J$ Biol Chem 278, 4096-4102.

44. Liuzzi JP, Blanchard RK \& Cousins RJ (2001) Differential regulation of zinc transporter 1, 2 and 4 mRNA expression by dietary zinc in rats. J Nutr 131, 46-52.

45. McMahon RJ \& Cousins RJ (1998) Regulation of the zinc transporter ZnT-1 by dietary zinc. Proc Natl Acad Sci U S A 95 , 4841-4846.

46. Dufner-Beattie J, Wang F, Kuo YM, et al. (2003) The acrodermatitis enteropathica gene ZIP4 encodes a tissue-specific, zinc-regulated zinc transporter in mice. $J$ Biol Chem 278, 33474-33481.

47. Chen WY, John JAC, Lin CH, et al. (2007) Expression pattern of metallothionein, MTF-1 nuclear translocation, and its DNAbinding activity in zebrafish (Danio rerio) induce by zinc and cadmium. Environ Toxicol Chem 26, 110-117.

48. Langmade SJ, Ravindra R, Daniels PJ, et al. (2000) The transcription factor MTF-1 mediates metal regulation of the mouse ZnT1 gene. J Biol Chem 275, 34803-34809.
49. Muylle F, Robbens J, De Coen W, et al. (2006) Cadmium and zinc induction of ZnT-1 mRNA in an established carp cell line. Comp Biochem Physiol C Toxicol Pharmacol 143, 242-251.

50. Eder K \& Kirchgessner M (1996) Effects of zinc deficiency on concentrations of lipids in liver and plasma of rats. Trace Elem Med 13, 60-65.

51. Abu-Elheiga L, Almarza-Ortega DB, Baldini A, et al. (1997) Human acetyl-CoA carboxylase 2 molecular cloning, characterization, chromosomal mapping, and evidence for two isoforms. J Biol Chem 272, 10669-10677.

52. Kerner J \& Hoppel C (2000) Fatty acid import into mitochondria. Biochim Biophys Acta 1486, 1-17.

53. Ibanez A, Peinado-Onsurbe J, Sanchez E, et al. (2008) Lipoprotein lipase (LPL) is highly expressed and active in the ovary of European sea bass (Dicentrarchus labrax), during gonadal development. Comp Biochem Physiol A Mol Integr Physiol 150, 347-354.

54. Rigault C, Le Borgne F, Tazir B, et al. (2013) A high-fat diet increases l-carnitine synthesis through a differential maturation of the Bbox1 mRNAs. Biochim Biophys Acta 1831, 370-377.

55. Yahagi N, Shimano H, Hasty AH, et al. (1999) A crucial role of sterol regulatory element-binding protein-1 in the regulation of lipogenic gene expression by polyunsaturated fatty acids. J Biol Chem 274, 35840-35844.

56. Ribet C, Montastier E, Valle C, et al. (2010) Peroxisome proliferator-activated receptor control of lipid and glucose metabolism in human white adipocytes. Endocrinology 151, 123-133.

57. Amemiya-Kudo M, Shimano H, Hasty AH, et al. (2002) Transcriptional activities of nuclear SREBP-1a,-1c, and-2 to different target promoters of lipogenic and cholesterogenic genes. J Lipid Res 43, 1220-1235.

58. Barish GD (2006) Peroxisome proliferator-activated receptors and liver $\mathrm{X}$ receptors in atherosclerosis and immunity. J Nutr 136, 690-694.

59. Rosen ED, Sarraf P, Troy AE, et al. (1999) PPAR $\gamma$ is required for the differentiation of adipose tissue in vivo and in vitro. Mol Cell 4, 611-617.

60. Shen H, MacDonald R, Bruemmer D, et al. (2007) Zinc deficiency alters lipid metabolism in LDL receptordeficient mice treated with rosiglitazone. J Nutr 137, 2339-2345. 